WellBeing International

WBI Studies Repository

4-15-2002

\title{
The use and abuse of Aesculapian authority in veterinary medicine
}

Bernard Rollin

Colorado State University, bernard.rollin@colostate.edu

Follow this and additional works at: https://www.wellbeingintlstudiesrepository.org/proveth

Part of the Animal Studies Commons, Bioethics and Medical Ethics Commons, and the Other Veterinary Medicine Commons

\section{Recommended Citation}

Rollin, B. E. (2002). The use and abuse of Aesculapian authority in veterinary medicine. Journal of the American Veterinary Medical Association, 220(8), 1144-1149. https://doi.org/10.2460/

javma.2002.220.1144

This material is brought to you for free and open access by WellBeing International. It has been accepted for inclusion by an authorized administrator of the WBI Studies Repository. For more information, please contact wbisr-info@wellbeingintl.org.

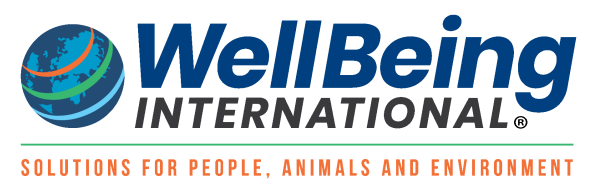




\title{
Commentary
}

\section{The use and abuse of Aesculapian authority in veterinary medicine}

\author{
Bernard E. Rollin, PhD
}

A Aesculapian Authority?

A the unique concept of Aesculapian authorityfessionals_-has long been implicitly recognized in human medicine, and explicitly articulated since the 1950 s, ${ }^{1}$ it has not been similarly applied to veterinary medicine. This is in part a function of the fact that, until recently, veterinary medicine was primarily and overwhelmingly focused on the economic value of animals, usually in agriculture, and that value defined and circumscribed the degree to which treatment was accorded to a sick animal. It is only since companion animal medicine has come to have a major role in veterinary medicine (and society has, to a much lesser extent, expressed concern about laboratory animals) that economic value of the animal as a constraint on expenditure for diagnosis and treatment has been superseded, and companion animals have come to be seen more as persons valued for their uniqueness. Fewer and fewer pet owners would be inclined to euthanatize Fifi, their pet Beagle, because it is cheaper to buy a new Beagle than fix the old one, though such a mindset would certainly be prevalent in agriculture, where animals bear primarily economic value. Since the early 1980s, for example, it is quite common for pet owners to spend tens of thousands of dollars at the Colorado State University veterinary hospital for cancer treatment.

In judicial decisions granting emotional damages for losses of animals and in explicit legislation, society has begun to acknowledge that companion animals possess more than market value. Municipal resolutions in San Francisco and Boulder, Colo, have affirmed the (currently legally indefensible) notion that humans are guardians, not owners, of companion animals, and numerous legal scholars are exploring various strategies for raising the legal status of animals from that of property.

Thus, as society moves away from an economic conception of companion animals, including horses, to a notion of family, veterinarians serving that population are forced (or, in most cases, given their personal predilections, are allowed to move) out of what I used to call a "garage mechanic" model of treating animals toward a "pediatrician" model. And with this new model of treating the animal as a direct object of moral

From the Department of Philosophy, Colorado State University, Fort Collins, CO 80523-1781. and medical concern, as opposed to a utilitarian object whose value is overwhelmingly economic, comes increasing relevance of the concept of Aesculapian authority to companion animal practice and correlative relevance of potential abuse of that authority.

What is Aesculapian authority? The locus classicus where the concept is most carefully analyzed is Siegler and Osmond's Models of Madness, Models of Medicine, where Aesculapian authority is discussed in the context of human physicians. ${ }^{1}$ According to their discussion, Aesculapian authority is the uniquely powerful authority vested in those that society perceives as healers, historically traceable to the time when medicine was inseparable from magic and religion. It is Aesculapian authority that licenses a medical practitioner to handle a patient with great intimacy. Physicians may probe all parts of the body of patients of either gender, with barely a "by your leave" - they tell a patient they must enter an otherwise forbidden area rather than ask for permission. Aesculapian authority confers the sick role, allowing patients to escape from responsibilities of work, school, or family. Such authority also compels patients to ingest unpalatable medications; change their eating or sleeping habits; submit to moral lectures on child rearing; surrender blood, urine, or fecal material; be immobilized; undergo surgery preceded by imposed loss of consciousness; or even change their temperament. What would be dismissed as torture in the absence of Aesculapian authority is meekly accepted by even the most powerful in its presence. As one physician once told me, "As a physician, I can get almost anyone to do whatever I tell him or her."

In fact, argue Siegler and Osmond, ${ }^{1}$ Aesculapian authority is far and away the most powerful authority in society-even kings, politicians, and dictators submit to medical authority they don't understand and can be scolded and ordered about by physicians.

According to Siegler and Osmond, ${ }^{1}$ this authority derives from a combination of traits-sapiential (ie, special wisdom and knowledge), moral (deriving from the overwhelming moral imperative to heal, relieve suffering, and retard death), and charismatic (derived from the fact that medicine is still related to magic in the eyes of the scientifically and medically naive). The latter explains why physicians are often threatened by dealing with medical students, veterinary students, or veterinarians-they know too much! 
Aesculapian authority is further reinforced by other members of the medical community as they rarely choose to call each other by first names around a patient or directly challenge the pronouncements of peers.

There are, however, strict limits to such authority. For example, it must be deployed to further the best interests of the patient; pursuit of any other end-such as extracting sexual favors from a patient-represents a clear-cut case of abuse of that authority. This creates ever-present moral problems of abuse of authority for physicians and researchers.

I believe everything said of physicians increasingly holds true of veterinarians; indeed many human patients seek medical advice and even assistance from their veterinarians, who are in fact held in higher esteem in society than are human medical doctors! ${ }^{a}$ Veterinarians too confer a sick role on animals and absolve them of tasks and responsibilities (particularly companion animals but also working animals), approach animals in all body parts and areas, perform operations that may be considered torturous outside of a medical context, and so on. The only difference, in fact, is that a veterinarian almost always works through a third party, the client and owner, whereas physicians usually work directly with patients. This is certainly not always true: consider pediatricians or those who practice gerontology or psychiatry-they too must often deal with a third party. But the key point is that, morally speaking, neither pediatricians nor companion animal veterinarians owe primary allegiance to the third party; their moral duty is to the patient, they are obliged by the nature of their profession to act in the best interest of the patient, and they consequently need to avoid orders or requests from the third party that are not in the best interest of the patient.

The major difference, of course, between pediatric physicians and veterinarians is the fact that the consensus social ethic will back the pediatrician in circumventing the obstructive third party, as when a parent refuses to allow a child to receive requisite medical care, courts will order it done. We have not yet reached that stage with animals. But insofar as the animal owner claims to be interested first and foremost in the health of the animal, the situation is logically the same for a pediatrician and (at least) the companion animal veterinarian.

Plato $^{2}$ made a highly relevant point in the Republic when he pointed out that, conceptually, the primary obligation of a shepherd is to further the well-being of the sheep in his purview. The money he makes accrues to him in his capacity as wage earner and does not take precedence over his primary obligation. Indeed, this analogy helps us to understand why we are so morally horrified at a shepherd who accepts a bribe to hurt or kill his sheep. By the same token, the veterinarian treating companion animals that owners view as persons or family members is obliged to give primacy to the animal.

This is not to deny that veterinary medicine is a people profession, for not working with the owner for the benefit of the animal can be a major problem. It is here that full Aesculapian authority can and should be invoked for the benefit of the animal. This may involve all of the elements of Aesculapian authority mentioned earlier: appeal to knowledge, wisdom, and experience; appeal to moral authority; and appeal to healer's charisma. The key point is that veterinary medicine can require great people skills and more time spent in dealing with owners than with actual diagnostic and therapeutic modalities performed on the animal, yet conceptually, the ultimate function and goal of veterinary medicine can still be the best interests of the animal.

One aspect of Aesculapian authority that has not been discussed in either human or veterinary medical contexts derives from concepts developed in the philosophy of language. During the mid-20th century, Oxford philosopher J. L. Austin ${ }^{3}$ (as well as numerous other linguistically oriented philosophers, including Wittgenstein) called attention to hitherto unnoticed dimensions of language beyond the descriptive-that is, beyond the uttering of descriptive statements that are true or false. In particular, Austin stressed the concept of performative utterances whereby a speaker, by virtue of his or her social role, performs an action beyond the linguistic when saying certain words. Examples abound. When an umpire says, "You're out," you are out, even if later examination of videotapes shows that you are factually safe. When a king says you are banished, you'd best be out of the kingdom forthwith. When a minister says, "I now pronounce you man and wife," only complex legal machinations can cancel the resulting state. And so on.

The ability to create powerful performative utterances accrues naturally to those possessed of Aesculapian authority. A physician or veterinarian is required to declare one sick and thereby create the sick role, with all its attendant removal of responsibility for person or animal. A psychiatrist who declares a person a possible danger to himself or others thereby creates indefinite commitment for a person without appeal, something even judges cannot do. A declaration from a public health veterinarian regarding foot-and-mouth disease, rabies, or bovine spongiform encephalopathy can effectively doom thousands of animals to death with no appeal.

Even outside the complex tissue of social regulations, a physician or veterinarian can create uniquely powerful performative utterances. We have all heard of people who, when told by a physician, "you have only six months to live," will obligingly die during that period (whereas others, less trustful of physicians, will make it a point to confute that prognosis). The same holds true of "you will never walk again" or "your animal will never walk again." To put it simply, for at least some people, a pronouncement made from a base of Aesculapian authority by a physician or a veterinarian becomes a self-fulfilling prophecy. Even if the veterinarian is physiologically wrong, many clients will not, after that pronouncement, attempt to have the animal walk, thereby, through lack of attempt or through subsequent muscle atrophy, validating the prognostication!

It follows from this discussion that Aesculapian authority is an extremely powerful notion and, like any other power, is subject to abuse. We are not interested 
in deliberate, self-conscious, intentional abuse, such as using that authority to extract sexual favors or money from patients or, in the case of veterinary medicine, from clients. We are rather concerned with the unconscious, nondeliberate abuse of this most powerful of authorities in virtue of lack of reflection on it, obliviousness to its full extent or influence, failure to recognize it is being deployed where it shouldn't be, or, equally pernicious, that it is not being deployed when it should. In what follows, we shall chronicle some examples of this sort of nondeliberate abuse of Aesculapian authority in the hope of making veterinarians more aware of this notion and its dangers.

\section{Issues of Euthanasia}

Probably the most common issues surrounding Aesculapian authority in veterinary medicine devolve around medical and convenience euthanasia. These issues come from two problems-clients who demand euthanasia for trivial reasons and clients who refuse euthanasia despite its being medically indicated to end suffering. Historically, the issue of greatest concern to veterinarians related to euthanasia has involved requests to perform convenience euthanasia for reasons the veterinarian perceives as unacceptable. Discussions with veterinarians and humane society workers reveal that pet owners may request euthanasia for appalling reasons: the animal no longer matches the color scheme; we are going on vacation and it is cheaper to get a new animal than to board it; the animal is getting old and can no longer run with me.

Veterinarians who lean toward the pediatrician model report that being asked to euthanatize healthypotentially healthy - animals is one of the most odious aspects of their job. Indeed, constantly performing such euthanasias is highly erosive of physical and mental health by virtue of the stress it engenders. It is moral stress ${ }^{4}$ based in a fundamental and inescapable belief that what you are doing is totally inimical to your professional reason for being, as you are asked to destroy healthy functional beings, many of whom you may have worked to save in the past.

Ordinary stress management techniques do not touch that stress. And if you are morally conscientious, it does not help much to send these clients packing, for you believe that someone will kill the animal for them. I have argued that the only escape from moral stress in the context of demands for convenience euthanasia is to do everything in one's power to save that animal, including exerting one's Aesculapian authority as forcefully as possible. Unfortunately, too many veterinarians, having been trained in a context where the mechanic model was prevalent, however much they may personally lean toward the moral primacy of animal interests, will perform the euthanasia. This leads not only to spirally escalating moral stress but helps perpetuate client expectations regarding the viability and moral acceptability of convenience euthanasia.

In short, I am arguing that failure to wield one's Aesculapian authority to save the life of an animal by acquiescing to requests for convenience euthanasia represents a substantial moral problem in veterinary medicine. This in turn cheapens animal life in the eyes of the public and validates irresponsibility. Failing to act is a form of acting, generating bad consequences for animals, society, individual veterinarians, and veterinary medicine in general.

Ironically, in many cases of convenience euthanasia, the veterinarian can save the animal if he or she uses the authority inherent in the healer role. If the euthanasia is for behavior problems, the veterinarian can recommend retraining, behavior modification, or pharmacologic intervention. If euthanasia is requested for the sort of bad reasons cited, the veterinarian can forthrightly indicate that he or she did not get a veterinary education to destroy healthy animals and can suggest other options-fostering, adoption, and so on. In my view, there is nothing wrong with a veterinarian educating a client regarding the ethical unacceptability of convenience euthanasia any more than there is anything wrong with pediatricians counseling against child abuse.

To accomplish these goals requires that veterinarians become consciously aware of their Aesculapian authority and learn to consciously deploy it. This in turn requires recognition and discussion of that authority by the veterinary community and incorporation of these issues into veterinary school curricula and continuing education.

It is likely that as society continues to evolve in the direction of what I have elsewhere called the "new ethic for animals," sia will gradually be mitigated, for societal disapproval of such euthanasia will help shape behavior, and education will influence subsequent generations. It is also not inconceivable that legislation growing out of this new ethic will make it more difficult to get rid of an animal. There is an analogy here with the rapid and revolutionary changes in social thought and behavior with regard to despoliation and preservation of the environment. In the 1960s, environmental concern was not a social issue; by 1970, we had experienced the first Earth Day.

Meanwhile, as more and more people in society profess to view their animals as members of the family, another and opposite problem for veterinarians has emerged. ${ }^{6}$ There are now ever-increasing numbers of people unwilling to surrender their animals to disease and sometimes unwilling to authorize medical euthanasia despite the animal's poor prognosis and high degree of suffering. Since the late 1970s, people have been spending large amounts of money on their companion animals' health, which has in turn driven the development of practices in oncology, surgery, cardiology, and other specialty fields. Such commitment to one's animals is often laudable but sometimes is pathologic and selfish, as when owners refuse to accept that the animal is in such a state of suffering that euthanasia is the moral course of choice yet are unwilling to let go because of their own emotional needs. Thus, in a given day, a morally aware veterinarian may face one client who wants a perfectly healthy dog killed and another who will not consider euthanasia of a terminally ill animal in pain.

This new attachment to animals is quite understandable. As divorces increase, as people live longer 
and longer, as our culture gets increasingly urban, loneliness grows epidemic, and the love and reciprocal care once provided in extended families vanish. An animal may be the only being to fill the human need for giving and receiving love or may be the only reason an elderly person has to wake up in the morning. Under such circumstances, it is easy to understand the temptation to keep the animal alive at all costs. Nonetheless, this raises a major problem for the veterinarian who sees his or her primary responsibility as serving the best interests of the animal.

It is true that reasons once believed definitive for justifying euthanasia have now been supplanted. Whereas, for example, amputation of a limb was believed to cause sufficient suffering and inadequacy for the animal as to justify euthanasia for the sake of the animal's welfare, we now realize that this is not the case. Such advances notwithstanding, however, it is well to remember that an animal consumed by pain may be incapable of fulfilling its nature and of being happy. Humans tell us that when they are in chronic, unalleviable pain, they are the pain; their other rolesparent, professional, friend, lover-are subordinated to the pain. How much the more so, then, for an animal that, lacking hope, cannot even imagine an end to the pain $?^{7}$

Should veterinary students be taught that they are not to direct clients toward euthanasia? It is claimed that a clinician who does so or even answers the question "what would you do?" is being paternalistic and directive and will likely be rejected by the client later with "you made me kill my dog." The client must make his or her own decision.

In my view, this is a grievous and mischievous error. One would not ask a client's opinion on what antibiotic or surgical approach to use. The same logic holds for euthanasia, which is, for the veterinarian adopting the pediatrician model, the ultimate treatment for otherwise unalleviable suffering. One would hope that veterinary education prepares a professional to judge when that situation is the case better than a layperson can. Thus, if one is committed to the best interests of the animal, one should not surrender deployment of the ultimate treatment for suffering to the clients, especially when they are focused on their own interests (ie, fear of loss of the animal on which they emotionally depend).

Thus, it is well within the role of veterinarian as healing professional to deploy his or her Aesculapian authority to keep a healthy animal alive; medicine aims at restoring or maintaining healthy living. Similarly, it is also conceptually part of the veterinarian's duty to end suffering totally erosive of the animal's quality of life. By no means should one be insensitive to the client's putative reasons for wanting to kill a healthy animal or keep alive a suffering one. But being sensitive to these reasons-and using one's Aesculapian authority to do so-does not mean that one should abrogate serving the best interests of the animal. It simply means learning to communicate that requirement to a client in a way that helps ease them. In the event that even Aesculapian authority cannot move the client to euthanasia, it should be deployed to convince the client to acquiesce to heroic pain control, which may in the end be tantamount to euthanasia yet easier to accomplish.

In our discussion thus far we have presupposed a long-term relationship between client and clinician, which sometimes makes it easier for the doctor to exert Aesculapian authority. But such a long-term relationship is not essential for such authority or presuppositional to it. A surgeon someone sees for moments before and after an operation may enjoy greater Aesculapian authority over a patient or client than a medical professional who is also a family friend. Thus a critical care veterinarian, encountering a client he or she does not know, is unsullied by intimate knowledge of client emotional reliance on the animal and can say "it is time to stop trying" with greater lack of ambiguity and ambivalence than can the veterinarian whose attention is focused in part on the human and who thus may be more sympathetic toward resolution of the situation not in the best interests of the animal.

Another problem relating to improper use of Aesculapian authority can arise when the clinician is also a researcher, as is the case with some oncologists whose research is performed on client-owned animals. This is a laudable approach to making progress in biomedicine, for it is far less problematic to use naturally existing disease than to create it in healthy animals. Yet such research runs the risk of the clinician's confusing roles.

As a clinician, the veterinarian's primary obligation is to the best interests of the animal. As a researcher, however, the veterinarian's primary obligation is to extract the most data from the experiment. These two functions may conflict when, qua researcher, the veterinarian is tempted to keep the suffering animal alive as long as possible to glean additional knowledge from the case. Yet qua clinician, the veterinarian knows that his or her obligation is to end the suffering. The same conflict is evident in the Veterinarian's Oath when one is asked to commit to advancing medical knowledge yet also to alleviating animal suffering. Danger exists when the veterinarian uses his or her Aesculapian authority with clients to move them toward prolonging life when the animal is suffering. Clinicians should not use their Aesculapian authority to justify actions that do not directly benefit their patients.

\section{The Problem of Informed Consent}

Similar problems may arise in human and veterinary medical research with regard to enrolling research subjects in clinical protocols. A physician surgeon involved in research once told me that in his view, there is often no real informed consent in such research. The same could hold true in veterinary research.

Guarding against this abuse of Aesculapian authority is difficult-and more difficult, ironically enough, for a client's companion animal being used in clinical research than for a research animal owned by the researcher. In the latter case, animal care and use committees demand end points for the research to control animal suffering. Such end points are almost always set before the advent of major pain or distress. 
Yet, in the case of clinical research, the end point may be left to the animal owner who, unlike the committee, may well confound the veterinarian researcher's separate and distinct roles as healer and researcher.

\section{Problems Arising Out of Confusing Wage Earner and Healer}

As mentioned, Plato points out that one's role as a healer should be kept separate from one's role as a wage earner, with the interests of the patient taking precedence. This distinction is easier to maintain in theory than in practice and may well become blurred, leading to abuse of Aesculapian authority. An example would be when you recommend an expensive diet that you stock to a client for a temporary usage, yet when the animal no longer needs the diet, you never explicitly tell the client that a different diet will work just as well. You are certainly not getting wealthy by virtue of your authority, but you are prolonging unnecessary expenditure. A similar point can be made with regard to recommending or even raising the issue of heartworm medicaments in an area where heartworm infection is unlikely.

\section{Problems of Alternative Medicine}

An emerging issue of Aesculapian authority is the degree to which that authority can be used to recommend treatments to clients or, more subtly, to validate their demands for such treatments. Consider the scenario of patients who believe the physician is holding something back that will cure or alleviate their symptoms. This paranoia seems to be common in society, and people are gravitating toward all sorts of clinically unproven regimens. ${ }^{8}$

Billions of dollars are spent annually on such nostrums, despite the fact that many were empirically discredited a century or more ago. There are good reasons for public disaffection with science-based medicineneglect by that tradition of psychological dimensions of sickness, failure of science-based physicians to focus on unique elements of disease embodied in a unique individual in favor of the law-like, iatrogenic problems coming out of medicine, the high cost of medication and medical care, the emphasis on cure over care, prolongation of life without regard to its quality, and so on. Such problems lead some of us to a search for simple solutions to medical problems. A sort of good old days mentality seizes some people's imaginations, and they yearn for natural or spiritual remedies, forgetting that arsenic, prions, and snake venom are all natural without thereby being healthful or even innocuous.

In any case, client demands for such treatments have increased to a fever pitch, pressure for veterinarians to supply them is overwhelming, and clients are willing to pay! Further, in some cases the disease you are to treat is in the client's imagination-they come to you for companionship, advice, counseling, or friendship under the aegis of having a sick animal. So what is the harm in prescribing alternative therapies that provide hope for clients, give them what they want, or may have a positive placebo effect, provided such remedies do no harm? Why shouldn't we place our Aesculapian authority behind these unproven remedies?
Many clinicians have begun to provide such therapies for a variety of reasons. These include: "The clients demand them" and "They will get them from somewhere; it might as well be me." Yet the concept of Aesculapian authority is seriously impeded by such reasoning, for one of the sources of that authority is one's medical expertise, based in the best knowledge one can garner. If one prostitutes that authority to endorse nonremedies posing as remedies, it can well lead to erosion of that authority, particularly when the social pendulum swings, as it inevitably will, away from fascination with therapies that have no basis in proof of efficacy and are, in many cases, incompatible with what we know of nature. Like one's reputation for veracity, medical credibility, once lost, is difficult to regain.

We may seek some guidance from the American Academy of Pediatrics, a highly relevant group of professionals who have examined this issue and whose results are clearly highly relevant for veterinarians who embrace the pediatrician model. In a recent publication, the American Academy of Pediatrics Committee on Children with Disabilities has developed guidelines for "Counseling Families Who Choose Complementary and Alternative Medicine for Their Child With Chronic Illness or Disability." These guidelines conceptually address many often-neglected aspects of disease and treatment. While acknowledging that all medical therapies, conventional or alternative, should be scienceand evidence-based, the guidelines wrestle sympathetically with the mindset leading desperate people to seek such therapies.

These guidelines stress the need for medical professionals not to relinquish their ability to influence treatment and serve the best interests of the child, that is, to retain their Aesculapian authority in their relationship with parents. That does not mean endorsing therapies that might be dangerous, but it does mean not relinquishing one's medical purview over the child. That in turn means being extremely sensitive to parental frustration, desperation, and overwhelming desire to do something. The practitioner should study the alternative modality sought by the client, critically evaluate the scientific basis of and evidence for the therapy in a sympathetic way, and forthrightly explain the likelihood of success as he or she sees it. This is likely to entail a discussion of types of evidence, the weakness of anecdote, or the compatibility with known laws of nature. Even more important, he or she should communicate possible dangers of these therapies:

Alternative therapies may be directly harmful by causing direct toxic effects, compromising adequate nutrition, interrupting beneficial medications or therapies, or postponing biomedical therapies of proven effectiveness. Indirect harm may be caused by the financial burden of the alternative therapy, other unanticipated costs (eg, the time investment required to administer therapy), and feelings of guilt associated with inability to adhere to rigorous treatment demands. If a child receiving alternative therapy is at direct or indirect risk of harm, the pediatrician should advise against the therapy. In some circumstances, it 
may be necessary for the pediatrician to seek an ethics consultation or to refer to child welfare agencies. If there is no risk of direct or indirect harm, a pediatrician should be neutral. ${ }^{9}$

To ensure that the animal comes to no harm, the veterinarian must be even more skillful than the pediatrician in displaying sensitivity to the client and in deploying Aesculapian authority, as animals do not have the legal protection children do.

The guidelines also suggest Aesculapian authoritybased discussions of improving quality of life for the patient. This can mitigate the hopelessness that leads people to try anything. Directing the family to support and advocacy groups relevant to the disease in question can be of value. In addition, the practitioner should not be cavalier in dismissing the alternatives but empathetic and open, not defensive. If the client insists on adopting an alternative modality, the practitioner should not disengage but offer to assist in monitoring and evaluating the response in a critical but sympathetic way.

In sum, while one should be careful about using one's Aesculapian authority in support of baseless therapies, it is perfectly appropriate to deploy it vigorously to address the reasons people turn toward alternatives. Empathetic concern with the uniqueness of the patient and client situation, reassurance, careful and sensitive communication, and discussion of quality of life, when conveyed with Aesculapian authority in an unhurried personal way, can all help alleviate the client's powerful need to seek these elsewhere. More empathy in human dimensions of medicine may well help to end people's desperate search for magic cures.

As Siegler and Osmond ${ }^{1}$ point out, Aesculapian authority is the most powerful authority one can have in society. As animals become increasingly personally and morally important in society, veterinary Aesculapian authority will increase. Indeed, as disaffection about human health care increases, veterinary Aesculapian authority will probably be augmented, with veterinarians serving as trusted authorities about medical matters.

Such authority is invaluable in furthering health but, as we have seen, is subject to inadvertent abuse. We may hope that increasing practitioner awareness of Aesculapian authority will help them to use it in a positive fashion.

${ }^{a}$ Knight AP, Department of Clinical Sciences, College of Veterinary Medicine and Biomedical Sciences, Colorado State University, Fort Collins, Colo: Personal communication, 1999.

\section{References}

1. Siegler M, Osmond H. Models of madness, models of medicine. New York: Harper Colophon, 1974;88-120.

2. Plato. The Republic. New York: Oxford University Press, 1941.

3. Austin JL. How to do things with words. New York: Oxford University Press, 1965;94-108.

4. Rollin BE. Euthanasia and moral stress. In: DeBellis R, ed. Loss, grief, and care. Binghamton, NY: Haworth Press, 1986; $115-127$.

5. Rollin BE. Farm animal welfare. Ames, Iowa: Iowa State University Press, 1995.

6. Rollin BE. Dogmatisms and catechisms. Anthrozoos 2001;14:4-11.

7. Rollin BE. The ethics of pain control in companion animals. In: Hellebrekers LJ, ed. Animal pain. Utrecht, Netherlands: Van Der Wees, 2000;17-39.

8. Schoen A, Wynn S. Complementary and alternative medicine: principles and practice. St Louis: CV Mosby Co, 1998.

9. American Academy of Pediatrics Committee on Children with Disabilities. Counseling families who choose complementary and alternative medicine for their child with chronic illness or disability. Pediatrics 2001;107:598-601. 